\title{
Quantitative Evaluation of Commercially Available Test Kit for Ciguatera in Fish
}

\author{
Paul Bienfang ${ }^{1}$, Suzanne DeFelice ${ }^{1}$, Anne Dowling ${ }^{2}$ \\ ${ }^{1}$ Center for Oceans and Human Health, Pacific Research Center for Marine Biomedicine, School of Ocean and Earth Science and Tech- \\ nology, University of Hawaii, Honolulu, USA; ${ }^{2}$ East Carolina University, Biology Department, Greenville, USA. \\ Email: bienfang@soest.hawaii.edu, adowling4@gmail.com
}

Received April 29 ${ }^{\text {th }}, 2011$; revised July $1^{\text {st }}, 2011$; accepted July $8^{\text {th }}, 2011$.

\begin{abstract}
Reliability of the commercially available Cigua-Check ${ }^{\circledR}$ test kits to identify ciguateric fish was evaluated by assessing the uniformity of conclusions by multiple readers examining identical sticks. One hundred and eighty-eight samples of two types of reef fish were tested for ciguatera using Cigua-Check ${ }^{\circledR}$ test strips. Paired subsamples of all specimens were also analyzed via the more rigorous $\mathrm{N} 2$ a neuroblastoma mouse bioassay that is specific for aberration of $\mathrm{Na}^{+}$-channel activity that is presumptive for ciguatera fish poisoning. In a double blind trial, four individuals visually examined identical Cigua-Check ${ }^{\circledR}$ strips to conclude whether the samples were positive or negative for ciguatera. Of the 121 samples that were shown to be positively ciguatoxic via bioassay, the four strip readers were in agreement in concluding positive ciguateric status in $9.9 \%$ of the samples; these four readers concluded these positive samples were negative for ciguatera in $26.2 \%$ of these bioassay-positive samples. Of the 67 samples that were shown in N2a bioassay to be negatively ciguatoxic, the four readers were in agreement in concluding a negative ciguateric status in $26.9 \%$ of the samples; these four strip readers concluded these same samples were positive for ciguatera in $14.9 \%$ of these negative samples. The low levels of uniform conclusions among readers examining identical test strips, and the low frequency of agreement with the correct ciguateric status as shown by separate N2a neuroblastoma analyses indicate severe shortcomings in the reliability of these test kits to accurately reflect the ciguateric status of samples. The level of uncertainty associated with Cigua-Check ${ }^{\circledR}$ test kits indicate a continuing need for improvement of a simple, rapid, and reliable means to identify ciguateric fish.
\end{abstract}

Keywords: Seafood, Ciguatera, Test, Fish, Hawaii

\section{Introduction}

Ciguatera fish poisoning (CFP) is a food-borne disease that affects coastal populations and travelers in tropical and subtropical regions; see also several reviews on CFP [1-4]. It is caused by the ingestion of coral reef fish that have accumulated a naturally-occurring marine toxin that is produced by dinoflagellates of the genus Gambierdiscus spp. The grazing of these dinoflagellates by herbivorous fish begins a processes of bioaccumulation and biomodification through the reef food web, as the herbivores are consumed by carnivores and ultimately by humans. Derived from gambiertoxins produced by Gambierdiscus spp., the congeners of ciguatoxin are polar, lipid-soluble, polyether compounds that are heat stable, tasteless, and odorless.

Ciguatera is a prominent problem for recreational and subsistence fishermen worldwide. Reported cases of CFP number at least 50,000 cases annually [5,6], but due to the high degree of misdiagnosis and underreporting, it is estimated that the actual frequency of CFP cases is closer to 500,000 per year $[7,8]$. It has been variously estimated that $25 \%-50 \%$ of the populations of islands in the Caribbean and South Pacific have suffered from CFP [9-12]. CFP incidents have been estimated to account for roughly five times the reported incidence for paralytic shellfish poisoning and neurological shellfish poisoning combined [13], and the economic impact from CFP has been estimated to exceed that from any other form of hazardous algae bloom [14].

Ciguatoxin produces gastrointestinal, neurological, and cardiovascular symptoms that may persist in some form for weeks, months, or longer [8,15-17]. The ciguatoxin is not affected by either cooking or freezing, and a 
ciguatoxic fish is not distinguishable by any visual or organolyptic signal, such as might be the case with fish tainted by bacteria. Clinical symptomologies in humans are elicited effective at extremely low (i.e. sub-ppb) ciguatoxin concentrations in fish. Analytical challenges to detection of ciguatoxin congeners have been central to the slow progress in development of routine methodologies both for research purposes and for practical applications by the public. Excellent summaries of various detection methods for ciguatera toxins are given by $[1,4]$.

A practical method for fishermen to identify ciguatoxic fish prior to serving caught fish to their families and/or sale to others is considered to be essential to the prevention of CFP. Because of the importance of reef fish in the diets of many island communities, and the high economic and community value placed on recreational fishing in tropical regions [14,18], there has been considerable interest globally in simple kits that could reliably identify ciguateric fish. Polyclonal antibodies in an assay for detecting haptens via a luminescent probe was pursued over years [19-21], and subjected to considerable analytical controversy [22-26]. Currently a ciguatera test kit, termed Cigua-Check ${ }^{\circledR}$, is marketed out of Hawaii. Anecdotal information from researchers and fishermen who used these kits portrayed shortcomings (i.e., false positives and false negatives) in their application. The objective of these trials was to quantitatively evaluate the practical usefulness of this prophylactic detection method for ciguatera by assessing the consistency with which multiply users of the kit would derive a similar conclusion regarding the ciguatoxic status of fish being examined.

\section{Materials and Methods}

Fish samples were collected from various locations within the Main Hawaiian Islands by local spearfishermen. 104 samples of the obligate carnivore, Cephalopholis argus, and 84 samples of the obligate herbivore, Acanthurus striatus, were examined using both the commercially available Cigua-Check ${ }^{\circledR}$ test kit and the $\mathrm{Na}^{+}$-channel specific N2a neuroblastoma mouse bioassay.

All fish were kept frozen prior to analyses for ciguatera, and evaluated within a double-blind sampling design. Cigua-Check ${ }^{\circledR}$ test kits were purchased from the vendor and used within the manufacturers recommended shelf life following instructions given on the box. Cigua$\mathrm{Check}^{\circledR}$ test kits claim a sensitivity of $0.10 \mathrm{ug} \mathrm{CTX} / \mathrm{kg}$ fish, which approximates the estimated lower threshold for clinical symptomology in humans.

The fish were also tested in triplicate at various concentrations via a sodium channel specific N2a bioassay, generally following the protocols given by [27-29]. This bioassay potentates depolarization of cellular membranes, and is used to elucidate sodium channel disruption such as would be caused by ciguatoxin. This procedure has a limit of detection of $0.05 \mathrm{ug}$ CTX $/ \mathrm{kg}$ fish. Ten grams of each fish were lyophilized, powdered, and extracted using methylene chloride. This process entails sonication and evaporation, followed by solubilization in methanol prior to dosing into 96-well plates. The standard doseresponse curve for the N2a bioassay is shown in Figure 1. The signal of the controls plus ouabain and veratridine was approximately $61 \%$ of the signal of the cells without ouabain and veratridine $(n=20)$. The relative standard deviation for the controls plus ouabain and veratridine $(n=$ 15 ) averaged $14 \%$, and the relative standard deviation for the various PCTX standards $(n=15)$ averaged $10.8 \%$. Results were computed and statistically analyzed using Students t-test [30] to identify significant differences between various controls $(n=10)$ and fish sample means $(n=5)$.

\section{Results}

Table 1 presents the compiled results of four individual Cigua-Check ${ }^{\circledR}$ readers' examination of the 188 fish samples together with the ciguatoxic status from the N2a bioassay analyses of those samples. The N2a analyses showed $70 \%$ and $57 \%$ of these carnivore and herbivore samples to be positive for ciguatera, respectively. Data show the frequencies for which the four readers were in agreement that a given sample was positive or negative

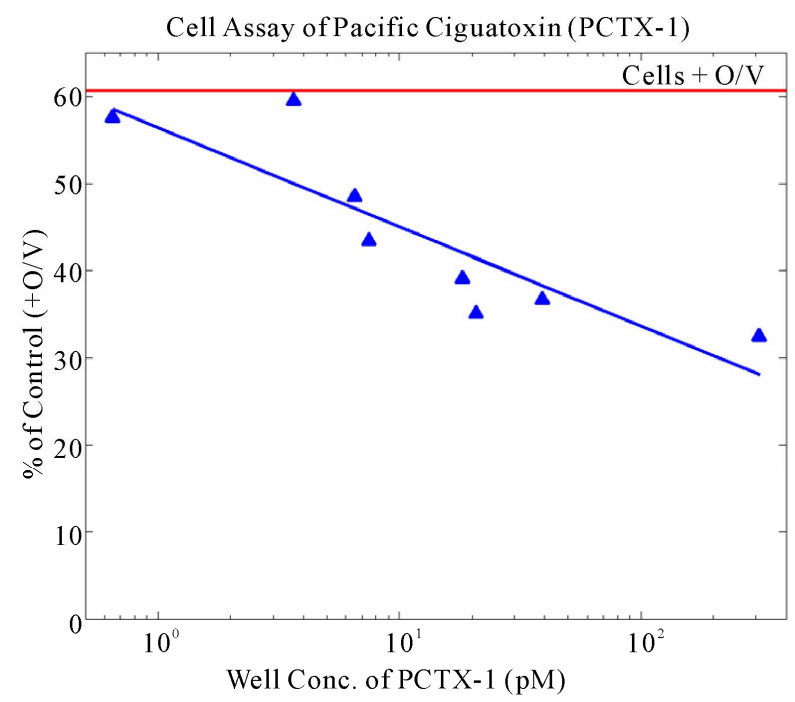

Figure 1. Dose-response curve for the N2a neuroblastoma bioassay to Pacific ciguatoxin. Signal strengths in response to a range of PCTX-1 concentrations are given as \% of control wells $(n=20)$ following addition of ouabain and veratridine. Relative standard deviations about the means for standards and controls averaged $11 \%$ and $14 \%$, respectively. 
Table 1. Summary data from four independent readers evaluating identical Cigua-Check ${ }^{\circledR}$ test sticks. Ciguatera status was determined by N2a Neuroblastoma Bioassays. $N$ gives the number of fish specimens that were evaluated. 4/4 (+) indicates that all four readers agreed that the samples were positive, and $4 / 4(-)$ indicates that all four readers agreed that the samples were negative, etc.

\begin{tabular}{|c|c|c|c|c|c|c|c|}
\hline \multirow{2}{*}{$\begin{array}{l}\text { Fish } \\
\text { Type }\end{array}$} & \multicolumn{2}{|l|}{ Ciguatera } & \multicolumn{5}{|c|}{ Results from Four Readers using Cigua-Check ${ }^{\circledR S t i c k s}$} \\
\hline & Status & $\mathbf{N}$ & $4 / 4(+)$ & $3 / 4(+)$ & $2 / 4(+)$ & $1 / 4(+)$ & $4 / 4(-)$ \\
\hline \multirow{2}{*}{ Carnivore } & Positive & 73 & $5.5 \%$ & $16.4 \%$ & $16.4 \%$ & $24.7 \%$ & $37.0 \%$ \\
\hline & Negative & 31 & $3.2 \%$ & $6.5 \%$ & $29.0 \%$ & $29.1 \%$ & $32.2 \%$ \\
\hline \multirow{2}{*}{ Herbivore } & Positive & 48 & $16.7 \%$ & $16.7 \%$ & $31.2 \%$ & $25.0 \%$ & $10.4 \%$ \\
\hline & Negative & 36 & $25.0 \%$ & $19.4 \%$ & $11.1 \%$ & $22.3 \%$ & $22.2 \%$ \\
\hline \multirow{2}{*}{ All } & Positive & 121 & $9.9 \%$ & $16.5 \%$ & $23.2 \%$ & $24.2 \%$ & $26.2 \%$ \\
\hline & Negative & 67 & $14.9 \%$ & $13.4 \%$ & $19.4 \%$ & $25.4 \%$ & $26.9 \%$ \\
\hline
\end{tabular}

(i.e., 4/4 (+) and 4/4 (-), respectively), and/or for which the three of the four readers were in agreement that a given sample was positive or negative (i.e., 3/4 (+) and $1 / 4(+)$, respectively).

Of the 73 carnivore samples that were positively ciguatoxic, the four readers were in agreement in concluding a positive ciguateric status in $5.5 \%$ of the samples; these same four readers were in unanimous agreement that these positively ciguateric samples were negative for ciguatera in $37.0 \%$ of these positive samples. Of the 31 carnivore samples that were negative for ciguatoxin, these four readers were in agreement in concluding the negative ciguateric status in $32.2 \%$ of the samples; these four readers were in unanimous agreement that these negatively ciguateric samples were positive for ciguatera in $3.2 \%$ of these negative samples. Of the 48 herbivore samples that were positively ciguatoxic, the four readers were in agreement in concluding a positive ciguateric status in $16.7 \%$ of the samples; these same four readers were in unanimous agreement that these positively ciguateric samples were negative for ciguatera in $10.4 \%$ of these positive samples. Of the 36 herbivore samples that were negative for ciguatoxin, the four readers were in agreement in concluding the negative ciguateric status in $22.2 \%$ of the samples; these four readers were in unanimous agreement that these negatively ciguateric samples were positive for ciguatera in $25.0 \%$ of these negative samples.

Overall, the four readers of the Cigua-Check ${ }^{\circledR}$ sticks were in total agreement (i.e., 4/4 +) in their assessment of the 121 positive ciguatoxic fish samples only $11.9 \%$ of the time, and they were in unanimous agreement (i.e., 4/4 -) in their assessment of the 67 negatively ciguatoxic fish samples only $26.9 \%$ of the time. For the 121 positive ciguatoxic samples, the frequency with which the four readers of the Cigua-Check ${ }^{\circledR}$ sticks were in unanimous but incorrect agreement of the ciguatoxic condition of the fish samples was approximately $100 \%$ greater than the correct determination. For the 67 negatively ciguatoxic samples, the four readers of the Cigua-Check ${ }^{\circledR}$ sticks were in unanimous but incorrect agreement of the ciguatoxic condition of the fish samples at a frequency which was approximately $55 \%$ of the correct determination.

\section{Discussion}

This study examined two indices of reliability of the Cigua-Check $^{\circledR}$ test strips to provide useful information with respect to the ciguatoxic status of fish samples. These indices included the degree to which multiple readers of the same test strip would be in agreement in their conclusions from their individual evaluations of identical Cigua-Check ${ }^{\circledR}$ sticks (i.e., operational error), and the degree to which such conclusions were consistent with the actual ciguateric status of those samples, as determined by a more robust laboratory evaluation of $\mathrm{Na}^{+}$-channel aberration provided by the N2a neuroblastoma bioassay. These results indicate that Cigua-Check ${ }^{\circledR}$ test strips present substantial deficiencies in the provision of a simple and reliable means for the recreational fisherman to distinguish ciguatoxic fish. Although a portion of the false negative signals obtained from comparison of the test strips with the N2a bioassay might be attributable to a greater sensitivity of the latter method, the low degree of agreement among readers of the same test strips indicates that serious ambiguity is associated with assessment of the test strip results by various individuals. In addition, the positive controls provided within the Cigua-Check ${ }^{\circledR}$ kits showed considerable variation in signal strength among kits. Moreover the recording of positive results (not shown) for test strips that were exposed to triplicate samples of orange roughly (i.e., a mesopelagic fish without a nutritional connection to reef food- 
webs), chicken, and two types of cheeses suggest that the development of blue coloration on the test sticks is highly non-specific. The crucial step to preventing ciguatera fish poisoning in humans remains the detection of ciguatoxin in fish. This need emphasizes the importance of a practical diagnostic tool for use by recreational and/ or subsistence fishermen. Development of a reliable field test continues to be a principal challenge for the prevention of ciguatera fish poisoning.

\section{Acknowledgements}

This research was made possible through the Centers for Oceans and Human Health $(\mathrm{COHH})$ program of the National Institute of Environmental Health Sciences (P50ES012740), and National Science Foundation and grants OCE04-32479, OCE09-11000, and OCE08-52301 from the National Science Foundation. The content is solely the responsibility of the authors and does not necessarily represent the official view of the National Institute of Environmental Health Sciences, the National Institutes of Health, or the National Science Foundation.

\section{REFERENCES}

[1] L. Lehane and R. J. Lewis, "Ciguatera: Recent Advances but the Risk Remains," International Journal of Food Microbiology, Vol. 61, No. 2-3, 2000, pp. 91-125. doi:10.1016/S0168-1605(00)00382-2

[2] P. K. Bienfang, M. L. Parsons, R. R. Bidigare, E. A. Laws and P. D. R. Moeller, "Ciguatera Fish Poisoning: A Synopsis from Ecology to Toxicity,” In: P. J. Walsh, S. L. Smith, L. E. Fleming, H. Solo-Gabriele and W. H. Gerwick, Eds., Oceans and Human Health: Risks and Remedies from the Sea, Elsevier Science Publishers, New York, 2008, pp. 257-270.

[3] R. W. Dickey, "Ciguatera Toxins: Chemistry, Toxicology and Detection," In: L. M. Botana, Ed., Seafood and Freshwater Toxins: Pharmacology, Physiology, and Detection, 2nd Edition, CRC Press, Boca Raton, 2008, pp. 479-500.

[4] R. W. Dickey and S. M. Plakas, "Ciguatera: A Public Health Perspective," Toxicon, Vol. 56, No. 2, 2010, pp. 123-136.

[5] J. P. Quod and J. Turquer, "Ciguatera in Reunion Island (SW Indian Ocean): Epidemiology and Clinical Patterns," Toxicon, Vol. 34, No. 7, 1996, pp. 779-785.

[6] R. J. Lewis, "The Changing Face of Ciguatera," Toxicon, 2001, Vol. 39, No. 1, pp. 97-106.

[7] J. Pearn, "Neurology of Ciguatera," Journal of the Neurological Sciences, Vol. 70, No. 1, 2001, pp. 4-8.

[8] P. Arena, B. Levin, L. E. Fleming, M. A. Friedman and D. G. Blythe, "A Pilot Study of the Cognitive and Psychological Correlates of Chronic Ciguatera Poisoning," Harmful Algae, Vol. 3, No. 1, 2004, pp. 51-60.

[9] R. J. Lewis, "Disease and Development: Ciguatera Fish
Poisoning," Social Science and Medicine, Vol. 23, No. 10, 1986, pp. 983-993.

[10] W. R. Lange, "Ciguatera Fish Poisoning," American Family Physician, Vol. 50, No. 3, 1994, pp. 579-584.

[11] L. E. Fleming, D. Katz, J. A. Bean and R. Hammond, "Epidemiology of Seafood Poisoning," In: Y. H. Hui, D. Kitts and P. S. Stanfield, Eds., Foodborne Disease Handbook, CRC Press, Boca Raton, 2001, pp. 287-310.

[12] L. E. Fleming, D. G. Baden, J. A. Bean, R. Weisman and D. G. Blythe, "Seafood Toxin Diseases: Issues in Epidemiology and Community Outreach," In: B. Reguera, J. Blanco, M. L. Fernandez and T. Wyatt, Eds., Harmful Algae, Zunta de Galicia and Intergovernmental Oceanographic Commission of UNESCO, 1998, pp. 245-248.

[13] K. A. Steidinger and D. G. Baden, "Toxic Marine Dinoflagellates," In: D. L. Spector, Ed., Academic Press, Orlando, 1985, pp. 210-261.

[14] H. Kite-Powell, "Public Health and Economic Implications of Oceans and Human Health Research," OHH Symposium and Workshop, Washington DC, 2010.

[15] J. Cameron, A. E. Flowers and M. F. Capra, "Electrophysiological Studies on Ciguatera Fish Poisoning in Men (Part II)," Journal of the Neurological Sciences, Vol. 101, No. 1, 1991, pp. 93-97. doi:10.1016/0022-510X(91)90022-Y

[16] E. Benoit, P. Juzans, A. M. Legrand and J. Molgo, "Reversal of Pacific Ciguatoxin-1B Effects on Myelinated Axons by Agents Used in Ciguatera Treatment," Cybium, Vol. 24, No. 3, 2000, pp. 33-40.

[17] M. A. Friedman, L. E. Fleming, M. Fernandez, P. Bienfang, K. Schrank, R. Dickey, M.-Y. Bottein, L. Backer, R. Ayyar, R. Weisman, S. Watkins, R. Grande and A. Reich, "Ciguatera Fish Poisoning: Treatment, Prevention and Management," Marine Drugs, Vol. 6, No. 3, 2008, pp. 456-479. doi:10.3390/md6030456

[18] D. Thompson, "Fight Club: Going after Ulua with Hawaii's Best Fishermen," Hana Hou, Vol. 13, No. 4, 2010, pp. 50-59.

[19] Y. Hokama, A. H. Banner and D. B. Boylan, "A Radioimmunoassay for the Detection of Ciguatoxin," Toxicon, Vol. 15, No. 4, 1977, pp. 317-325. doi:10.1016/0041-0101(77)90014-9

[20] Y. Hokama, “A Rapid, Simplified Enzyme Immunoassay Stick Test for the Detection of Ciguatoxin and related Polyethers," Toxicon, Vol. 23, No. 6, 1985, pp. 939-946. doi:10.1016/0041-0101(85)90386-1

[21] Y. Hokama, W. E. Takenaka, K. L. Mishimura, J. S. Ebesu, R. Bourke and P. K. Sullivan. "A Simple Membrane Immunobead Assay for Detecting Ciguatoxin and Related Polyethers from Human Ciguatera Intoxication and Natural Reef Fishes," Journal of the AOAC International, Vol. 81, No. 4, 1998, pp. 727-735.

[22] D. L. Park, "Evaluation of Methods for Assessing Ciguatera Toxins in Fish," Reviews of Environmental Contamination and Toxicology, Vol. 136, 1994, pp. 1-20.

[23] R. W. Dickey, H. R. Granade and F. D. McClure, "Eva- 
luation of the Ciguatect Solid-Phase Immunobead assay for the Detection of Ciguatera-Related Biotoxins in Caribbean Finfish," Proceedings of the International Workshop on Ciguatera Management, Brisbane, Vol. 34, No. 3, 1994, pp. 481-488.

[24] A.-M. Legrand, T. Teai, P. Cruchet, M. Satake, K. Murata and T. Yasumoto, "Two Structural Types of Ciguatoxins Involved in Ciguatera Fish Poisoning in French Polynesia," In: B. Reguera, J. Blanco, M. L. Fernandez and T. Wyatt, Eds., Harmful Algae, Xunta de Galicia and InterGovernmental Commission of UNESCO, 1998, pp. 473-475.

[25] S. Pauillac, M. Sasaki, J. Naar, M. Inoue, P. Branaa, P. Cruchet, M. Chinain and A.-M. Legrand, "Immunochemical Methods for Ciguatoxins Detection in Pacific Herbivorous and Carnivorous Fish," In: B. Seret and J.-Y. Sire, Eds., Proceedings of the 5th Indo-Pacifique Fisheries Conference, Noumea, Society of French Ichthyologists, Paris, 1999, pp. 759-773.

[26] C.-K. Wong, P. Hung, K. L. H. Lee and K.-M. Kam, "Study of an Outbreak of Ciguatera Fish Poisoning in Hong Kong," Toxicon, Vol. 46, No. 5, 2005, pp. 563-571. doi:10.1016/j.toxicon.2005.06.023

[27] R. L. Manger, L. S. Leja, S. Y. Lee, J. M. Hungerford and
M. M. Wekell, "Tetrazolium-Based Cell Bioassay of Neurotoxins Active on Voltage-Sensitive Sodium Channels: Semiautomated Assay for Saxitoxins, Brevetoxins, and Ciguatoxins," Analytical Biochemistry, Vol. 214, No. 1, 1993, pp. 190-194. doi:10.1006/abio.1993.1476

[28] R. L. Manger, L. S. Leja, S. Y. Lee, J. M. Hungerford, Y. Hokama, R. W. Dickey, H. R. Granade, R. Lewis, T. Yasumoto and M. M. Wekell, "Detection of Sodium Channel Toxins: Directed Cytotoxicity Assays of Purified Ciguatoxins, Brevetoxins, Saxitoxins, and Seafood Extracts," Journal of AOAC International, Vol. 78, No. 2, 1995, pp. 521-543.

[29] R. W. Dickey, E. Jester, R. Granade, D. Mowdy, C. Moncrief, D. Rebarchik, M. Robl, S. Musser and M. Poli, "Monitoring Brevetoxins during a Gymnodinium Breve Red Tide: Comparison of Sodium Channel Specific Cytotoxicity Assay and Mouse Bioassay for Determination of Neurotoxic Shellfish Toxins in Shellfish Extracts," Natural Toxins, Vol. 7, No. 4, 1999, pp. 157-165. doi:10.1002/(SICI)1522-7189(199907/08)7:4<157::AIDNT52>3.0.CO;2-\#

[30] G. W. Snedecor and W. G. Conchran, "Statistical Methods," 7th Edition, The University Press, Ames, 1980, pp. $1-507$. 